\title{
DEVELOPMENT OF A MEASUREMENT TOOL TO EVALUATE THE LEARNING EXPERIENCE IN AN E-LEARNING SYSTEM
}

\author{
Yassine Safsouf 1,3 , Khalifa Mansouri ${ }^{2}$ and Franck Poirier ${ }^{1}$ \\ ${ }^{1}$ Lab-STICC, University Bretagne Sud, France \\ ${ }^{2}$ Laboratory SSDIA, ENSET of Mohammedia, University Hassan II of Casablanca, Morocco \\ ${ }^{3}$ LIMIE Laboratory, ISGA Group, Centre Marrakech, Morocco
}

\begin{abstract}
The purpose of this study is to find ways to monitor and evaluate the user experience of learners as they use an e-learning system. To do this, we have identified several factors that allow us to measure this experience. We have designed an online measurement scale, presented as a self-administered questionnaire, specifically dedicated to e-learning platforms. With this tool, we can quickly isolate aspects that are perceived as critical, and that often require improvement actions. Finally, we tested our measurement tool over two sessions of an online course. The results of statistical analysis are very encouraging, showing that the learning platform used is considered simple by learners, flexible, secure and encouraging autonomy. The results also show that the platform has a deficit of social interaction (interactions between learners and their teachers, as well as between pairs), which should be remedied in order to improve learners' experience.
\end{abstract}

\section{KEYWORDS}

User Experience, Learning Management System, UX Scales, Learning Experience, FASER LX Test

\section{INTRODUCTION}

User experience (UX) refers to the lived or anticipated user experience in all its dimensions. This has been much confused with usability, which is described by the International Organization for Standardization (ISO) as the extent to which a product can be used by specified users to achieve specified goals with effectiveness, efficiency and satisfaction in a specified context of use (ISO9241-11, 1998), while UX deals with all aspects of the user experience before, during and after interaction with a product, service, environment or company (ISO9241-210, 2010). These two aspects are inseparable from each other in order to have a positive user experience. In the field of e-learning, the use of a digital learning platform is indispensable. These learning platforms, often called LMS (Learning Management System) platforms, allow managers to design, deploy and share online learning resources to make them accessible any time and from anywhere. In addition to sharing and exchanging resources, these platforms allow the efficient monitoring of e-learning actions (individually and in groups) through advanced analyses and integrated course reports. This makes it possible to identify points in the course that do not correspond to learners' expectations. However, even though the use of LMSs probably has an added value for the learner, the absence of commitment and motivation can leave the learner unsatisfied and lead him/her to stop his online training.

The term learning experience (LX), refers to the overall experience that a learner has in a setting where learning takes place, in a traditional academic environment (such as a school, classrooms), or in a non-traditional environment (outside-of-school locations, online training). An LMS that has a poor LX may diminish the sense of quality of the overall programmes, leaving the learner frustrated and not very engaged in his or her training. In this regard, this article is intended to clarify the following issues:

- What factors measure the learning experience?

- How can the LX be evaluated? 
This article is divided into 5 sections: following this introduction, in the next section, we review the literature to determine the factors that will be used to measure LX. Section 3, presents our measurement tool, designed for LMS, to evaluate and monitor the improvement of the learning experience in an online course. Section 4, describes the methodology adopted to collect and analyze the study data, followed by a discussion of the results obtained. Finally, a conclusion with some limitations of this study is discussed in section 5.

\section{UX MEASUREMENT FACTORS}

The term UX was originally coined in the 1990s by the American cognitive psychologist Donald Norman. His books have made the term very popular in the scientific community specializing in human-computer interaction (HCI). In his book "The Design of Everyday Things", Donald Norman states that the term UX encompasses all aspects of interaction with a product or service, including factors related to emotional and hedonic aspects (Norman, 2004). In 1991, the User Experience Professional Association (UXPA) was created to present and defend user experience as a new discipline. This association defines (www.uxpa.org) UX as every aspect of user interaction with a product, service or company that constitutes the user's perception of practical aspects such as utility, usability and system efficiency, as well as the emotional aspects of a person using a particular product, system or service. In the UX literature, many definitions are proposed, according to Jakob Nielsen, UX brings all aspects of the end-user's interaction with the company, its services and products (Nielsen, 1999). He added that the concept of usability of a system is based on 5 criteria, namely: efficiency (the ease with which the user achieves his/her objective), satisfaction, ease of learning, memorability, and safety (low error rate). Another definition, proposed by Leena Arhippainen and Marika Tähti of the University of Oulu, Finland, presents UX as, the experience a person may obtain when interacting with a product under particular conditions (Arhippainen and Tähti, 2003). They also explain that UX is the result of the interaction of five categories of factors: user-related factors, social factors, cultural factors, contextual user factors and product factors. Marc Hassenzahl \& Noam Tractinsky, two researchers in the field of HCI and interaction design, argue that the term UX is associated with a wide variety of meanings, ranging from traditional usability (pragmatic aspects), to beauty, hedonic, affective or experiential aspects of technology use (Hassenzahl and Tractinsky, 2011). Based on these qualities, Hassenzahl created a UX measurement tool called AttrakDiff (Hassenzahl, Burmester and Koller, 2003). The latter includes 28 questions (normal version) or 10 questions (shortened version), divided into 4 sub-scales (pragmatic, hedonic-stimulation, hedonic-identity and overall attractiveness).

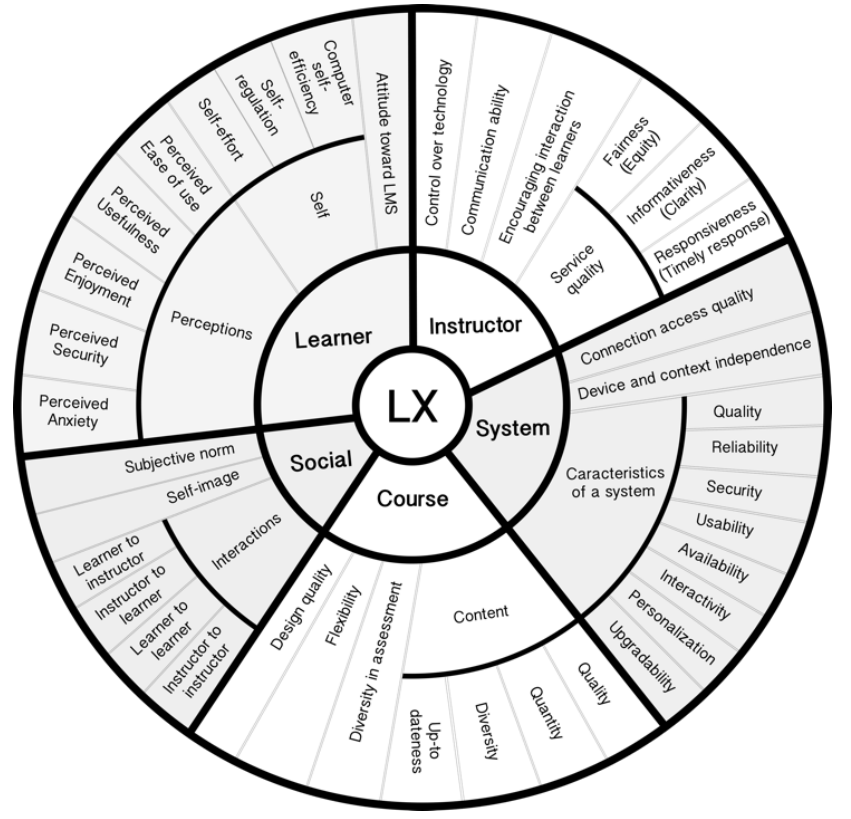

Figure 1. Dimensional measurement factors for learning experience 
An empirical study in which Kasper Hornbæk and Morten Hertzum, investigate the relationship between the TAM (Technology Acceptance Model) (Venkatesh and Davis, 2000) and UX (Hornbæk and Hertzum, 2017). The factors selected were classified into three categories: experiential and utilitarian aspects (anxiety, design aesthetics, cost, perceived usefulness, actual usage, behavioural intention), individual and social aspects (attitude towards use, curiosity, perceived critical mass, trust, system quality, subjective norm) and perceptual and objective aspects (excitement, intention to use, satisfaction, age, gender, mode of use, facilitating conditions, unplanned purchases).

In our previous research (Safsouf, Mansouri and Poirier, 2018, 2019, 2020), we identified and classified several factors, which allowed us to explain satisfaction, self-regulation, intention to continue using and success in an LMS. These factors were derived from several models: the TAM3 model (Venkatesh and Bala, 2008), the Expectation Confirmation Model (ECM) (Bhattacherjee, 2001), the DeLone and McLean Information Success Systems Model (D\&M ISS) (Delone and Mclean, 2003) and the Self-Regulated Learning Theory (SRL) (Zimmerman, 2013), (Panadero, 2017). Figure 1 presents our research framework.

Five dimensions were proposed for an initial classification, which are: learner factors (characteristics of learners that influence the adoption of the LMS), system factors (characteristics of the LMS platform), instructor factors (characteristics of instructors that play an important role in the perception of the effectiveness of the system), course factors and social factors (characteristics of the social environment in which learning activities take place). A second classification was done to highlight the pragmatic and hedonic aspects of these factors. Five qualities were proposed: pragmatic qualities (the system's manageability and how it enables users to achieve their objectives), "hedonic-stimulation" qualities (stimulation of the learner initiated by the system), "hedonic-satisfaction" qualities (feeling of satisfaction provided by the system), quality of effort (effort deployed when using the system), and finally, quality of social interaction (a user's social interactions with the actors of the LMS). Table 1 presents the factors for measuring UX in relation to the use of LMS and summarizes our proposed classification.

Table 1. Factors to measure the learning experience

\begin{tabular}{|c|c|c|c|c|c|}
\hline & \multirow{2}{*}{ Pragmatic } & \multicolumn{2}{|c|}{ Hedonic } & \multirow{2}{*}{ Effort } & \multirow{2}{*}{ Social } \\
\hline & & Stimulation & Satisfaction & & \\
\hline Learner & $\begin{array}{l}\text { Computer self-efficiency, } \\
\text { Self-regulation }\end{array}$ & Perceived usefulness & $\begin{array}{l}\text { Perceived enjoyment, } \\
\text { Self-security }\end{array}$ & $\begin{array}{c}\text { Self-effort, } \\
\text { perceived anxiety }\end{array}$ & \\
\hline Instructor & & Responsiveness & & Informativeness & $\begin{array}{c}\text { Communication ability, } \\
\text { Fairness }\end{array}$ \\
\hline System & $\begin{array}{c}\text { Connection access quality, } \\
\text { Efficiency, reliability, } \\
\text { Perceived ease-of-use, } \\
\text { Usability, Availability, } \\
\text { Personalization }\end{array}$ & Interactivity & & $\begin{array}{l}\text { device and } \\
\text { context } \\
\text { independence }\end{array}$ & \\
\hline Course & Diversity in assessments & $\begin{array}{l}\text { Content diversity, } \\
\text { Up-to-dateness. }\end{array}$ & $\begin{array}{l}\text { Design quality and } \\
\text { system quality }\end{array}$ & $\begin{array}{l}\text { Course quality, } \\
\text { course flexibility }\end{array}$ & \\
\hline Social & & & Self-image & & $\begin{array}{l}\text { Subjective norm, } \\
\text { Learner-learner } \\
\text { interaction, Learner- } \\
\text { instructor interaction and } \\
\text { Instructor-instructor } \\
\text { interaction. }\end{array}$ \\
\hline
\end{tabular}

\section{LX MEASURING SCALE}

The main objective of this study is to improve the learning experience of our learners during their training, but it is still necessary to know how to evaluate it. UX scales are among the most widely used instruments for evaluating UX. These measurement tools, often self-administered questionnaires, either paper or online, provide a quick indication of whether your system is perceived as innovative, effective, reliable or challenging. 
The AttrakDiff survey (Hassenzahl, Burmester and Koller, 2003), is one of the most widely used tools. Initially developed in German, translated and validated in French (Lallemand et al., 2015), it presents the items in the form of semantic differentiators to be assessed using 7-point Likert scales ranging from -3 to +3 .

In this article, we propose a measurement tool for LMS platforms to evaluate and monitor the improvement of the learning experience in an online course. We have chosen to call it "FASER LX Test" for "Formation, Apprenant, Système, Enseignant, Relation Learning eXperience" from the French acronym (Course, Learner, System, Teacher, Relationship). Table 2 shows the items chosen by factor.

Table 2. The 30 items of the FASER LX scale

\begin{tabular}{|c|c|c|c|}
\hline \multirow{2}{*}{$\begin{array}{c}\text { SUCCESS FACTORS } \\
\text { Computer self-efficiency }\end{array}$} & \multicolumn{3}{|c|}{ ANTONYM PAIRS } \\
\hline & Autonomous & - & Non-autonomous \\
\hline Self-enjoyment & Unpleasant & - & Pleasant \\
\hline Perceived usefulness & Boring & - & Captivating \\
\hline Self-effort & Undemanding & - & Demanding \\
\hline Self-regulation & Free use & - & Compulsory use \\
\hline Self-security & Confident & - & Distrustful \\
\hline Perceived anxiety & Calming & - & Stressing \\
\hline Communication ability & Easy communication & - & Difficult communication \\
\hline Responsiveness & High reactivity & - & Low reactivity \\
\hline Informativeness & Not comprehensible & - & Comprehensible \\
\hline Fairness & Unfair & - & Highly fair \\
\hline Connection access quality & Slow & - & Fast \\
\hline Device and context independence & Device dependent & - & Device independent \\
\hline Efficiency & Tedious & - & Efficient \\
\hline Reliability & Unreliable & - & Very reliable \\
\hline Perceived Ease-of-use & Difficult learning & - & Easy learning \\
\hline Availability & Not available & - & Very available \\
\hline Interactivity & Not interactive & - & Very interactive \\
\hline Personalization & Customizable & - & Not customizable \\
\hline Course Quality & Confused & - & Clear \\
\hline Content diversity & Not diversified & - & Very divided \\
\hline Course Flexibility & Rigid & - & Flexible \\
\hline Design and system quality & Pleasant & - & Unpleasant \\
\hline Up-to-dateness & Static & - & Dynamic \\
\hline Diversity in assessments & Diversified assessment & - & Not diversified assessment \\
\hline Subjective norm & Recommendable & - & Not recommendable \\
\hline Self-image & Valuable & - & Non-valuable \\
\hline Learner-learner interaction & Gets closer to learners & - & Separates me from learners \\
\hline Learner-instructor interaction & Get closer to teachers & - & Separate me from teachers \\
\hline Instructor-instructor interaction & Bring teachers together & - & Separate teachers \\
\hline
\end{tabular}

Like AttrakDiff, FASER LX is composed of questions in the form of opposite adjectives, each representing factors presented above (see Table 1). FASER LX is self-administered and available online in two languages: in French (www.safsouf.net/fr/faserlx/) and in English (www.safsouf.net/en/faserlx/). The items do not have the same valence (sometimes the word on the left is positive and sometimes it is negative). Before calculating a score, it is therefore necessary to make sure that the items are scored in the same direction. 


\section{RESEARCH METHOD}

\subsection{Data Collection}

In this article, we chose to evaluate the learning experience provided by the Moodle platform, in an online course entitled "Object-Oriented Programming", over a six-week period.

The participants are all students of the 1st year of the computer engineering cycle, from a private higher education institution (ISGA Campus of Marrakesh). The target class is composed of 25 students (32\% female and $68 \%$ male), aged between 18 and 35 years (76\% between 18 and 25 years and $24 \%$ between 26 and 35 years). In terms of computer usage time per day, $8 \%$ reported using the computer one to two hours per day, $16 \%$ between two and five hours, $68 \%$ between five and ten hours, and $8 \%$ more than ten hours per day. Regarding their computer skills levels, $8 \%$ expressed being novice, $52 \%$ intermediate, $32 \%$ advanced and $8 \%$ expert.

\subsection{Data Analysis}

In order to evaluate and monitor the improvement of our students' online learning experience, we tested the FASER LX Test in two periods. The first was during the second week of the course. The second was during the final week of the course. The data collected was analyzed using SPSS v. 23. New variables representing the dimensions and qualities (see Table 1) were created and calculated as the average (Avg) of the different associated factors. We also calculated the standard deviation (SD) of these new variables, in order to see the homogeneity of our participants' responses. Table 3 detail the results obtained with the percentage of improvement noted.

Table 3. Summary of the results obtained by dimensions and qualities

\begin{tabular}{|c|c|c|c|c|c|c|}
\hline & & \multirow{2}{*}{\multicolumn{2}{|c|}{ 2nd week }} & & & \\
\hline & & & & \multicolumn{2}{|c|}{ 6th week } & \multirow[t]{2}{*}{ Progress $\%$} \\
\hline & & $\mu$ & $\sigma$ & $\mu$ & $\sigma$ & \\
\hline \multirow{5}{*}{ 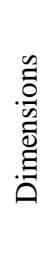 } & Learner & 3.868 & 0.542 & 4.468 & 0.653 & $+8.57 \%$ \\
\hline & Instructor & 4.660 & 0.831 & 4.678 & 0.798 & $+0.25 \%$ \\
\hline & System & 4.365 & 0.675 & 4.605 & 0.674 & $+3.42 \%$ \\
\hline & Course & 4.520 & 0.567 & 4.733 & 0.783 & $+3.04 \%$ \\
\hline & Social & 4.656 & 0.596 & 4.528 & 0.752 & $-1.82 \%$ \\
\hline \multirow{5}{*}{ 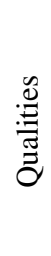 } & Pragmatic & 4.205 & 0.543 & 4.845 & 0.625 & $+9.14 \%$ \\
\hline & Hedonic-stimulation & 4.120 & 0.612 & 4.780 & 0.617 & $+9.42 \%$ \\
\hline & Hedonic-satisfaction & 3.744 & 0.932 & 4.104 & 0.910 & $+5.14 \%$ \\
\hline & Effort & 4.840 & 0.902 & 5.106 & 0.844 & $+3.80 \%$ \\
\hline & Social interaction & 4.566 & 0.666 & 4.606 & 0.898 & $+0.57 \%$ \\
\hline
\end{tabular}

The FASER LX Test measurement tool, offers a visualization of the results obtained in the form of a radar chart for the whole class. As shown in figures 2 and 3, two radar diagrams are generated. The first one shows the average of the percentage factors grouped by dimension. The second diagram represents the average of the percentage factors grouped by grade. The FASER LX also offers an individual visualization of the results obtained. The graphs obtained are the same as for the whole class, but this visualization is not discussed in this article.

This method of representation has the advantage of quickly distinguishing aspects (of the learner, the instructor, the system, the course or the social environment) which are perceived as critical, and which may or may not call for short or long-term improvement actions. 


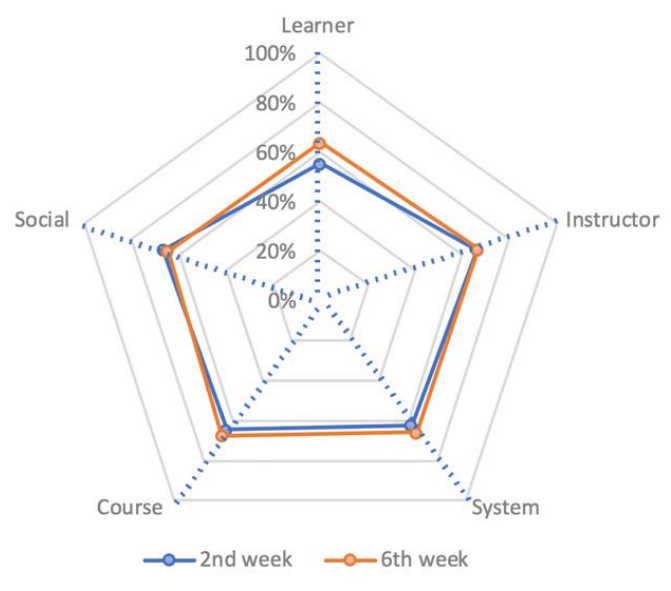

Figure 2. Result of the FASER LX Test by dimensions

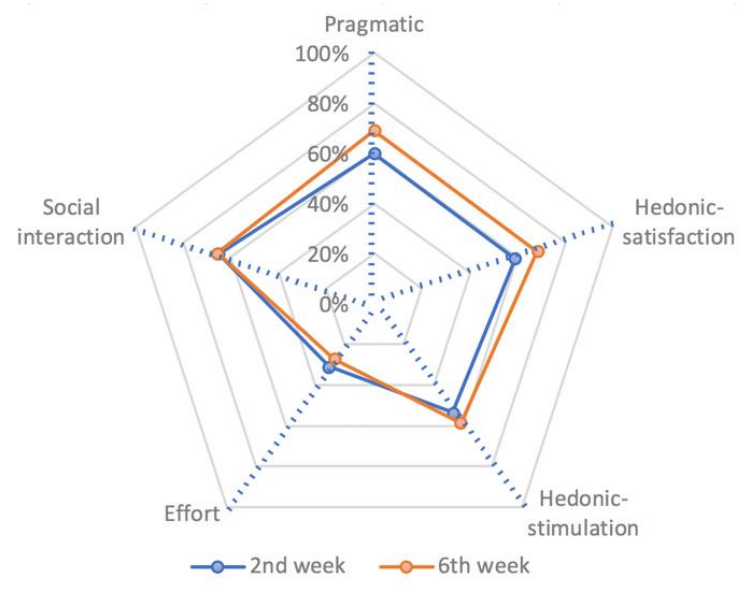

Figure 3. Result of the FASER LX Test by qualities

\subsection{Discussion of Results}

Based on the results of the statistical analysis presented in Table 3, as well as the ranking of the factors measuring the learning experience (Table 1 and Figure 1), we note an improvement of $8.57 \%$ for the factors composing the "learner" dimension with an increase of $9.14 \%, 9.42 \%$ and $5.14 \%$ respectively for the pragmatic, hedonic-satisfaction and hedonic-stimulating qualities. This means that the factors affected by this improvement are, computer self-efficiency, self-regulation, perceived usefulness, self-enjoyment and self-security. In other words, towards the end of the course, learners understood the usefulness of online training, and they claim to feel increasingly secure and autonomous using the platform. There was also an improvement in effort (3.80\%), indicating that learners now put in less effort and are less stressed.

The " Instructor" dimension showed almost no improvement $(0.25 \%)$, which means that learners didn't perceive any change in the level of the instructor. The results also indicate a small improvement in both dimensions "System" (3.42\%) and "Course" (3.04\%). This means that the factors affected by the improvement are, perceived efficiency, perceived ease-of-use, availability, course flexibility and diversity of content and assessments.

Finally, for the "Social" dimension, we noted a slight decrease $(-1.82 \%)$, explained by the fact that no interaction was recorded in the online course, neither with the teacher nor with peers. This confirms that collaborative learning is essential and should be encouraged in an online course.

\section{CONCLUSION AND LIMITATIONS}

The objective of this research is to identify factors that can be used to measure the learning experience of online learners in order to improve it. We have identified several factors, grouped according to five dimensions (learner, instructor, system, course and social). On the basis of these factors, an online measurement tool was created to evaluate this experience. Named FASER LX Test, it is composed of five sub-scales (pragmatic qualities, hedonic-satisfaction qualities, hedonic-stimulation qualities, qualities of effort and social qualities). The results of a study conducted during two periods of an online course show that learners found the platform rather easy to use, functional, reliable, flexible, and encouraging self-regulation.

Although this study identifies a few factors that can be used to measure the e-learning experience, several limitations should be noted. The first is that the sample is limited to a single class. Conducting the study in multiple classrooms would require greater resources. Due to the small number of participants, more detailed statistical analyses were not conducted. Finally, this study is limited to e-learning in the private education sector in Morocco and did not include the public education sector. These limitations may constitute an obstacle to the generalization of the results obtained. Future studies should also be conducted in the public sector. 


\section{REFERENCES}

Arhippainen, L. and Tähti, M. (2003) 'Empirical evaluation of user experience in two adaptive mobile application prototypes', Proceedings of the 2nd international conference ..., pp. 27-34. Available at: http://www.ep.liu.se/ecp/011/007/ecp011007.pdf.

Bhattacherjee, A. (2001) 'Understanding Information Systems Continuance: An Expectation-Confirmation Model', MIS Quarterly, 25(3), p. 351. doi: 10.2307/3250921.

Delone, W. . and Mclean, E. r. (2003) 'the Delone and Mclean model of information sys- tems success: A ten-year update', Journal of Management Information Systems. 19th, 4th edn, pp. 9-30.

Hassenzahl, M., Burmester, M. and Koller, F. (2003) 'AttrakDiff: Ein Fragebogen zur Messung wahrgenommener hedonischer und pragmatischer Qualität', J.Ziegler \& G. Szwillus (Eds.), Mensch \& Computer, pp. 187-196.

Hassenzahl, M. and Tractinsky, N. (2011) 'Behaviour \&amp; Information Technology User experience-a research agenda User experience-a research agenda'. doi: 10.1080/01449290500330331.

Hornbæk, K. and Hertzum, M. (2017) 'Technology acceptance and user experience: A review of the experiential component in HCI', ACM Transactions on Computer-Human Interaction, 24(5). doi: 10.1145/3127358.

ISO9241-11 (1998) Ergonomic requirements for office work with visual display terminals (VDTs), Part 11: Guidance on usability. Available at: https://www.iso.org/fr/standard/16883.html.

ISO9241-210 (2010) Ergonomics of human-system interaction, Part 210: Human-centred design for interactive systems. Available at: https://www.iso.org/standard/52075.html.

Lallemand, C. et al. (2015) 'Création et validation d'une version française du questionnaire AttrakDiff pour l'évaluation de l'expérience utilisateur des systèmes interactifs', Revue Europeenne de Psychologie Appliquee. Elsevier Masson SAS, 65(5), pp. 239-252. doi: 10.1016/j.erap.2015.08.002.

Nielsen, J. (1999) Designing Web Usability: The Practice of Simplicity. New Riders PublishingPost Office Box 4846 Thousand Oaks, CAUnited States.

Norman, D. A. (2004) Designers and Users: Two Perspectives On Emotion and Design. doi: 10.1007/BF02065545.

Panadero, E. (2017) 'A Review of Self-regulated Learning: Six Models and Four Directions for Research.', Frontiers in psychology, 8(April), p. 422. doi: 10.3389/fpsyg.2017.00422.

Safsouf, Y., Mansouri, K. and Poirier, F. (2018) 'A New Model of Learner Experience in Online Learning Environments', Information Systems and Technologies to Support Learning. Springer International Publishing, 111(Lx), pp. 29-38. doi: 10.1007/978-3-030-03577-8

Safsouf, Y., Mansouri, K. and Poirier, F. (2019) 'Design of a new scale to measure the learner experience in e-learning systems', Multi Conference on Computer Science and Information Systems, MCCSIS 2019 - Proceedings of the International Conference on e-Learning 2019, pp. 301-304. doi: 10.33965/el2019_201909c042.

Safsouf, Y., Mansouri, K. and Poirier, F. (2020) 'AN ANALYSIS TO UNDERSTAND THE ONLINE LEARNERS' SUCCESS IN PUBLIC HIGHER EDUCATION IN MOROCCO', Journal of Information Technology Education: Research, 19(2020), pp. 87-112. doi: https://doi.org/10.28945/4518.

Venkatesh, V. and Bala, H. (2008) 'Technology Acceptance Model 3 and a Research Agenda on Interventions', Decision Sciences, 39(2), pp. 273-315.

Venkatesh, V. and Davis, F. D. (2000) 'A Theoretical Extension of the Technology Acceptance Model: Four Longitudinal Field Studies', Management Science, 46(2), pp. 186-204. Available at: http://pubsonline.informs.org/doi/abs/10.1287/mnsc.46.2.186.11926 (Accessed: 16 January 2018).

Zimmerman, B. J. (2013) 'From Cognitive Modeling to Self-Regulation: A Social Cognitive Career Path', Educational Psychologist, 48(3), pp. 135-147. 